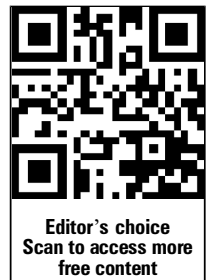

${ }^{1}$ South Central Ambulance Service, Otterbourne, UK

${ }^{2}$ NIHR Southampton

Respiratory Biomedical

Research Unit, University of Southampton, Southampton Hampshire, UK

${ }^{3}$ Shackleton Department of Anaesthetics, University Hospital Southampton, Southampton, UK ${ }^{4}$ Department of Cardiology, University Hospital Southampton, Southampton, UK

\section{Correspondence to} Professor Charles D Deakin, South Central Ambulance Service, Southern House, Sparrowgrove, Otterbourne, Hampshire SO21 2RU, UK; charles.deakin@scas.nhs.uk

Received 30 September 2013 Revised 5 December 2013 Accepted 6 December 2013 Published Online First 19 February 2014

\section{Linked}

- http://dx.doi.org/10.1136/ heartjnl-2013-305356

To cite: Deakin $C D$, Shewry E, Gray HH. Heart 2014;100:619-623.

\title{
Public access defibrillation remains out of reach for most victims of out-of-hospital sudden cardiac arrest
}

\author{
Charles D Deakin, ${ }^{1,2}$ Elizabeth Shewry, ${ }^{3}$ Huon $\mathrm{H} \mathrm{Gray}^{4}$
}

\begin{abstract}
Introduction Public access defibrillation (PAD) prior to ambulance arrival is a key determinant of survival from out-of-hospital $(\mathrm{OOH})$ cardiac arrest. Implementation of PAD has been underway in the UK for the past 12 years, and its importance in strengthening the chain of survival has been recognised in the government's recent 'Cardiovascular Disease Outcomes Strategy'. The extent of use of PAD in $\mathrm{OOH}$ cardiac arrests in the UK is unknown. We surveyed all $\mathrm{OOH}$ cardiac arrests in Hampshire over a 12-month period to ascertain the availability and effective use of PAD.

Methods A retrospective review of all patients with $\mathrm{OOH}$ cardiac arrest attended by South Central Ambulance Service (SCAS) in Hampshire during a 1-year period (1 September 2011 to 31 August 2012) was undertaken. Emergency calls were reviewed to establish the known presence of a PAD. Additionally, a review of all known PAD locations in Hampshire was undertaken, together with a survey of public areas where a PAD may be expected to be located.
\end{abstract}

Results The current population of Hampshire is estimated to be 1.76 million. During the study period, 673 known PADs were located in 278 Hampshire locations. Of all calls confirmed as cardiac arrest $(n=1035)$, the caller reported access to an automated external defibrillator (AED) on 44 occasions (4.25\%), successfully retrieving and using the AED before arrival of the ambulance on only 18 occasions (1.74\%).

Conclusions Despite several campaigns to raise public awareness and make PADs more available, many public areas have no recorded AED available, and in those where an AED was available it was only used in a minority of cases by members of the public before arrival of the ambulance. Overall, a PAD was only deployed successfully in $1.74 \% \mathrm{OOH}$ cardiac arrests. This weak link in the chain of survival contributes to the poor survival rate from $\mathrm{OOH}$ cardiac arrest and needs strengthening.

\section{INTRODUCTION}

Sudden cardiac arrest (SCA) accounts for approximately 30000 out-of-hospital $(\mathrm{OOH})$ events per annum in the UK. ${ }^{1}$ The sudden, unpredictable and geographically challenging nature of this emergency makes rapid treatment difficult, and with every minute's delay without resuscitation, mortality increases by $7-10 \% .^{2}$ These factors weaken the first three of four links in the Chain of Survival (early recognition and call for help, early cardiopulmonary resuscitation (CPR) and early defibrillation $)^{1}$ and contribute to the poor survival to hospital discharge rates of $2-12 \%$ across England. ${ }^{2}$ SCA remains a significant health issue, being recognised in the recent Cardiovascular Disease Outcomes Strategy as a priority area for improved care. ${ }^{3}$

With the UK ambulance service's performance indicator being a response to at least $75 \%$ of cardiac arrest within $8 \mathrm{~min}$, bystander resuscitation provides a vital therapeutic bridge while awaiting the arrival of trained responders and can increase survival rates twofold to threefold. ${ }^{4-6}$ The additional availability of an automated external defibrillator (AED) to allow bystanders to deliver defibrillation prior to the arrival of emergency medical service (EMS) through public access defibrillation (PAD) improves survival still further. ${ }^{7-10}$ The use of AEDs before the arrival of the EMS is associated with almost a doubling of survival after $\mathrm{OOH}$ cardiac arrest. ${ }^{11}$

With the knowledge that PAD is safe and effective when used by members of the public even with minimal or no first aid training, ${ }^{12}$ AEDs have become more common in public places. Local and government programmes have aimed to make AEDs available in areas of high-population density such as shopping centres and transport hubs where they are likely to see service. The introduction of AEDs has now been underway for more than a decade and parallels the growing awareness of the public for immediate resuscitation following sudden collapse, fuelled by campaigns such as the recent 'push hard, push fast campaign' narrated by Vinnie Jones. ${ }^{13}$ The first recommendation that PADs were an important contributor to outcome from SCA came in the Government policy paper of 1999 'Saving lives-our healthier nation', ${ }^{14}$ and at about this time, the BHF began placing some PADs in public areas. In 2000, the Department of Health (England) and the British Heart Foundation introduced a formal PAD programme, placing 681 AEDs in 110 public places for use by volunteer lay first responders. ${ }^{15} 16$ This achieved AED placement within 3-5 min of collapse in most cases, and within the first 4 years of the programme, 250 of the defibrillators had been used to deliver a least one shock, with 44 patients subsequently surviving to discharge.

More recently, the government's 'Cardiovascular Disease Outcomes Strategy', published in March 2013, has set as its aim to improve acute care by (inter alia) working to “...promote automatic external defibrillators (AED) site mapping/registration and first responder programmes by ambulance services and consider ways of increasing the numbers trained in cardiopulmonary resuscitation (CPR) and using AEDs". 3 
Early studies of PAD suggested that the few AEDs available were actually underused even when trained bystanders were on scene, ${ }^{717}$ and although distribution of AEDs is increasing, ${ }^{8} 1819$ little is known about the current availability and use of AEDs in the community. With clearly documented survival benefits of PAD programmes, it is important to understand how the early links in the chain of survival can be strengthened. We therefore reviewed all known $\mathrm{OOH}$ cardiac arrests in Hampshire, a county with a population of 1.76 million spread across a typical UK mix of urban and rural communities, in order to ascertain AED availability and use during $\mathrm{OOH}$ cardiac arrests that occurred over a 12-month period. We have not surveyed AEDs provided by community first responders (CFR) who are dispatched by the ambulance service ahead of the ambulance arrival, as these trained responders use mobile defibrillators in a more formal response. We have also surveyed the availability of AEDs particularly in areas of high public density.

\section{METHODS}

\section{Study design}

A retrospective review of all patients with documented cardiac arrest on scene in Hampshire, attended by South Central Ambulance Service (SCAS) during a 1-year period (1 September 2011 to 31 August 2012), was undertaken. Calls were reviewed to establish the known presence of a PAD. There are a number of differing definitions of what constitutes a 'public access defibrillator'. We have used a broad definition to encompass all defibrillators that are placed in the community and healthcare institutions (doctors surgeries, nursing homes, etc.) that may be available to individuals (both members of the public and those attending healthcare institutions) suffering a cardiac arrest outside hospital, prior to arrival of a formal ambulance response.

Additionally, a review and mapping of all known PAD locations in Hampshire were undertaken, together with a survey of public areas where a PAD may be expected to be located.

\section{System overview}

South Central Ambulance Service NHS Foundation Trust (SCAS) was established in 2006 following the merger of four ambulance trusts in the counties of Berkshire, Buckinghamshire, Hampshire and Oxfordshire. SCAS now covers approximately 3554 sq. miles, with a residential population of over four million. The emergency operations centre receives approximately 500000 emergency and urgent calls each year.

Within the SCAS area, Hampshire covers 1400 sq. miles, comprising a mixed urban and rural population of 1.76 million, with approximately $12 \%$ being aged over 70 years.

\section{Evaluation of 999 calls}

All 999 emergency calls made to SCAS are recorded electronically, and details of the call stored on a central database. The nature of the call is classified according to Advanced Medical Priority Dispatch (AMPDS) categorisation, enabling interrogation of the database to identify probable cardiac arrest calls.

All incidents identified as a probable cardiac arrest in Hampshire from 1 September 2011 to 31 August 2012 were identified from a total of 217463 emergency ambulance calls. These incidents were cross-referenced with the subsequent ambulance Patient Clinical Record to identify those where the attending ambulance crew confirmed a cardiac arrest on their arrival.
Identification of public AED (PAD) availability and use

For emergency calls from locations other than a private address, the ambulance call taker specifically asks the caller whether there is a defibrillator at the location. If the response if affirmative, further directions are given to encourage the caller to locate and use the PAD. The SCAS database records whether a PAD was available and whether it was used prior to the ambulance crew arrival. We recorded when the caller was aware of a PAD being available, when the PAD was located and its subsequent use.

\section{Survey of public AED locations in Hampshire}

SCAS maintains a database of known PADs, which is available to ambulance call takers and is aimed at improving PAD use. These locations, as at October 2012, were reviewed.

Additionally, we reviewed areas of high public density and clinical facilities in Hampshire, identified as having a greater chance of a cardiac arrest being witnessed. ${ }^{20} 21$

We undertook an internet search for specific public facilities in Hampshire, focusing on public sites know to be common locations for cardiac arrests, ${ }^{20}$ including airports, train stations, sporting facilities and schools. Direct contact was made with these identified organisations and establishments to ascertain whether a PAD was available.

\section{RESULTS}

\section{Identification of public AED (PAD) availability and use}

During the year 1 September 2011 to 31 August 2012, SCAS recorded in Hampshire a total of 1035 calls confirmed as cardiac arrests. This equates to one $\mathrm{OOH}$ cardiac arrest, per 600 members of the public, per annum.

At 44 of the 1035 cardiac arrests (4.25\%), the caller was aware of an AED being available at that location. The 44 cardiac arrests occurred in 34 different locations.

Of these 44 cardiac arrests, the AED was retrieved and attached to the patient in 18 cases $(40.9 \%)$ prior to the arrival of SCAS or a CFR. Thus, overall a PAD was successfully deployed prior to arrival of the trained responders at $1.74 \%$ of all cardiac arrests.

\section{Survey of public AED locations in Hampshire}

In October 2012, SCAS were aware of 278 locations where a total of 673 PADs were available in Hampshire. Thirty locations within Hampshire had more than one PAD. Table 1 lists common PAD locations in Hampshire according to type of property. All large shopping complexes had multiple PADs available.

Table 1 Common public access defibrillator (PAD) locations in Hampshire, listed by type of property and ranked by numbers

\begin{tabular}{ll}
\hline Type of property & Number of PADs \\
\hline Shopping centre & 146 \\
General commercial & 129 \\
Dwelling & 92 \\
GP surgery & 86 \\
Health centre & 37 \\
Nursing home & 22 \\
Golf & 11 \\
Sportlleisure centre & 9 \\
Residential homes & 5 \\
\hline
\end{tabular}


Table 2 Percentage of main public facilities within Hampshire with a known public access defibrillator (PAD) (*estimate), ranked by $\%$ PAD availability

\begin{tabular}{lcc}
\hline & Number of facilities & No. of PADs (\%) \\
\hline Commercial airport & 1 & $1(100)$ \\
Police station & 14 & $7(50)$ \\
Football stadiums & 2 & $1(50)$ \\
GP surgeries & 177 & $86(48.6)$ \\
Major bus terminal & $6^{*}$ & $2\left(33.3^{*}\right)$ \\
University & 4 & $1(25)$ \\
Golf courses & 66 & $11(16.7)$ \\
Nursing homes & 173 & $22(12.7)$ \\
Local government offices & $45^{*}$ & $4\left(8.9^{*}\right)$ \\
Train stations & 52 & $3(5.8)$ \\
Community centres/village hall & 40 & $2(5)$ \\
Library & 53 & $2(3.8)$ \\
Dentists & 195 & $1(0.5)$ \\
Primary schools & 135 & $5(3.7)$ \\
Secondary education & 60 & $2(3.3)$ \\
\hline
\end{tabular}

Table 2 lists public locations identified as areas where a PAD may be of particular benefit, ${ }^{20} 21$ together with details of known PADs at corresponding Hampshire locations. There are 52 train stations of varying sizes within Hampshire, but only three AEDs are located at these sites (South West Trains, personal communication, 2011).

\section{DISCUSSION}

With early defibrillation forming a key link in the chain of survival, and mortality increasing $7-10 \%$ for every minute's delay in defibrillation, the ability of bystanders to undertake basic life support and deploy a PAD prior to ambulance arrival significantly increases the chances of successful defibrillation and subsequent survival. The safety and benefits of PAD programmes for the estimated 6000-12 000 UK patients who suffer SCA in public places are now well established and, where implemented, can double survival from $\mathrm{OOH}$ cardiac arrest. ${ }^{22}$

These benefits have been recognised by the Department of Health, British Heart Foundation and Resuscitation Council (UK), for the past decade, all of whom have supported the introduction of PAD schemes across the UK. The recent Department of Health's 'Cardiovascular Disease Outcomes Strategy' (a document endorsed by Government, NHS England and Public Health England) has also recognised the need to “... consider ways of increasing the numbers trained in cardiopulmonary resuscitation (CPR) and using AEDs". We are unaware of any UK study examining the public use of AEDs nor any recent study examining the availability of AEDs in the community, which is important to ascertain if this important strategy is to be developed.

Overall, less than $2 \%$ of all $\mathrm{OOH}$ cardiac arrest victims had potential access to a PAD (although it is likely that at some cardiac arrests PADs were available but their presence unknown by the rescuer), and of those who did, only approximately $1 \%$ benefitted from its actual deployment. This disappointingly low figure is of the same magnitude as that recently reported by London Ambulance Service, where only 31/9657 (0.32\%) cardiac arrests benefitted from $\mathrm{PAD}^{23}$ and similar to the $2.1 \%$ reported from the USA overall, ${ }^{11}$ where similar PAD programmes have been introduced. Although distribution of AEDs is increasing, ${ }^{8} 18$ the usage rate is poor, even when trained bystanders are on scene. ${ }^{7} 17$ We found that when a PAD was known to be available, it was only used in $40.7 \%$ of cases. The reasons for this are unclear but appear related to a lack of bystander willingness to use an AED in an emergency situation, poor 'visibility' or accessibility of the AED, mistaken concerns over legal liabilities and poor levels of community knowledge about PAD, ${ }^{24}$ even following campaigns to improve public awareness. ${ }^{25}$ It would appear that there remains a significant barrier with public perception and education regarding the use of PADs.

Although the frequency of use of deployed PADs is relatively low, there is an inverse relationship between the geographic density of PADs and the time to first shock, with a positive relationship to survival. ${ }^{8}$ Where PADs are available, they are generally placed on the patient within $3-5$ min. ${ }^{19}$ At the time of the study, the location of the nearest AED for each cardiac arrest was unknown. Matching the cardiac arrest location to PAD coverage would be a useful undertaking in future studies in order to ascertain whether geographic distribution of PADs could be optimised.

With SCAS median ambulance response times to cardiac arrest calls of $6 \mathrm{~min}$, the majority of patients with $\mathrm{OOH}$ cardiac arrest should receive defibrillation prior to ambulance arrival in locations where a PAD is available and used. Ambulance call takers now routinely question the caller about the availability of a PAD in order to prompt PAD use if available. In addition to wider availability of AEDs, a more comprehensive national system for recording the presence and site of an AED, accessible to all ambulance services and to bystanders who witness an arrest, could greatly improve survival rates from $\mathrm{OOH}$ cardiac arrest.

The commonest location for an $\mathrm{OOH}$ cardiac arrest outside the private home is a care home, which accounts for approximately $10 \%$ of cardiac arrests. ${ }^{23}$ We identified a total of 18 PADs located at 658 registered care homes in Hampshire, ${ }^{26}$ representing only $2.7 \%$ of all care homes. Cardiac arrests occurring on public transport systems are also relatively common, particularly at railway stations. ${ }^{15} 2327$ This contrasts with the very few PADs available on the Hampshire railway network, particularly considering the large number of passengers passing through rail stations or travelling on trains. During 2011-2012, people entered or left Hampshire's busiest station (Southampton Central Station) ${ }^{28}$ on 5951224 occasions, a location without a PAD. Almost as common a location for an $\mathrm{OOH}$ cardiac arrest is a leisure or sports facility, ${ }^{23}$ but only 9 of the estimated 68 facilities (13.2\%) had a known PAD available. Although schools contain a mostly fit and healthy population, SCA, particularly during exercise, is known to occur as a result of inherited cardiac conditions. With approximately 400000 primary and secondary school children in Hampshire, ${ }^{29}$ we were disappointed that so few schools had a PAD available. This is a missed opportunity to educate school children about the benefits of bystander resuscitation and use of PADs, particularly as a greater awareness of PAD benefits would be likely to translate into greater placement of devices in the future.

In estimating the number of PADs in Hampshire, our telephone survey relied on contacted individuals passing accurate information. A number of the institutions contacted appeared unsure as to whether a PAD was available, reinforcing suggestions that education of potential users is a priority. We may therefore have underestimated the availability of a PAD at some locations, although PAD equipment is unlikely to be used if staff are unaware of its existence. This study has not examined the benefits of rapid defibrillation by CFR who are dispatched by the ambulance service ahead of the ambulance arrival. Although 
CFR delivery of an AED generally takes longer than that achieved through PAD, it does offer some prospect of resuscitation for many patients who would otherwise receive no treatment. $^{19}$

This study demonstrates that PAD is not available or is not used for the vast majority (over 98\%) of people suffering an $\mathrm{OOH}$ SCA in Hampshire. While we have not surveyed other parts of the UK, we believe our findings would probably be similar elsewhere. There are relatively few PAD devices available, and when they are, there is a lack of confidence by the lay public in using them. As a consequence, a real opportunity to save lives is missed. Greater numbers of PADs are required to improve rapid deployment at $\mathrm{OOH}$ SCA, and more people should be trained in their use and in basic life support techniques. It is impractical to deploy PADs to cover the entire population, but any location that has 1000 adults over the age of 35 years present during normal business hours can expect one incident of SCA every 5 years ${ }^{30}$-a threshold that has been suggested as a level at which a PAD should be available.

From February 2007, responsibility for continuing the legacy of the National Defibrillator Programme was devolved to ambulance trusts. Although most ambulance trusts across the UK have community resuscitation departments or similar, these generally raise funds for AEDs and community responders schemes rather than AEDs placed in fixed locations in public areas. Fund raising campaigns to increase PAD availability should be commended, and the government has been petitioned to introduce defibrillators to all public buildings by 2017, together with providing staff with the appropriate training (http://epetitions.direct.gov. uk/petitions/29399). The need for a centrally coordinated database to maximise PAD availability is clear, preferably accessible

\section{Key messages}

\section{What is already known about this subject?}

Public access defibrillation (PAD) prior to ambulance arrival is a key determinant of survival from out-of-hospital $(\mathrm{OOH})$ cardiac arrest. Implementation of PAD has been underway in the UK since the late 1990s, with many public areas now having access to a community defibrillator. The importance of PAD has been recognised by the British Heart Foundation, Resuscitation Council and, more recently, the current DH 'Cardiovascular Disease Outcomes Strategy'.

\section{How might this impact on clinical practice?}

The poor survival rates from $\mathrm{OOH}$ cardiac arrest are in part related to delays in defibrillation. More defibrillators are required in public areas and more education is needed to give bystanders the confidence to use the PAD when it is available. Ambulance services also need to update and use PAD location knowledge to improve use of PADs.

\section{What does this study add?}

Despite several campaigns to raise public awareness and make PADs more available, many public areas have no recorded automated external defibrillator (AED) available, and in those where an AED was available it was only used in a minority of cases by members of the public before arrival of the ambulance. Overall, a PAD was deployed successfully in only $1.74 \% \mathrm{OOH}$ cardiac arrests. This weak link in the chain of survival contributes to the poor survival rate from $\mathrm{OOH}$ cardiac arrest and needs strengthening. to the ambulance service, so that whenever an $\mathrm{OOH}$ cardiac arrest is identified, the operator can immediately advise of an AED location. Improving confidence by members of the public in using the PAD would also appear to be a priority for successful deployment. Further, PAD publicity should focus on the safety, effectiveness and ease of use of AEDs and counter perceived fears over litigation if used by the public 'inappropriately', which are unfounded and hinder wider use.

This study highlights the need for both improved PAD availability and the need to improve bystander confidence in the use of these devices. With survival from $\mathrm{OOH}$ cardiac arrest doubling in cases where PAD is used, ${ }^{11}$ there is a need to improve PAD availability, publicise locations and support bystanders in deploying the device. $\mathrm{OOH}$ cardiac arrest and PAD is an area appropriately prioritised by the Cardiovascular Disease Outcomes Strategy. ${ }^{3}$

Acknowledgements We thank the Performance Information Team of South Central Ambulance Service for collating the AED usage data. We also thank Magnus Hannah for his assistance with data collection.

Contributors CDD conceived the study and is guarantor. ES and CDD collated and analysed the data. All authors discussed, drafted and revised the manuscript.

Competing interests All authors have completed the Unified Competing Interest form at http://www.icmje.org/coi_disclosure.pdf (available on request from the corresponding author) and declare the following interests: CDD-Divisional Medical Director, South Central Ambulance Service; Immediate past Co-Chair, Advanced Life Support, ILCOR; Director, Prometheus Medical. HHG-National Clinical Director for Cardiac Disease, NHS England.

Ethics approval Not required.

Provenance and peer review Not commissioned; externally peer reviewed.

\section{REFERENCES}

1 Nolan JP, Soar J, Zideman DA, et al. European resuscitation council guidelines for resuscitation 2010 Section 1. Executive summary. Resuscitation 2010;81:1219-76.

2 Perkins GD, Cooke MW. Variability in cardiac arrest survival: the NHS ambulance service quality indicators. EMJ 2012;29:3-5.

3 Cardiovascular Disease Outcomes Strategy. Improving outcomes for people with or at risk of cardiovascular disease. Department of Health, 2013. http://www.gov.uk/ government/publications/improving-cardiovascular-disease-outcomes-strategy

4 Stiell IG, Nesbitt LP, Nichol G, et al. Comparison of the cerebral performance category score and the Health Utilities Index for survivors of cardiac arrest. Ann Emerg Med 2009;53:241-8.

5 SOS-KANTO Study Group. Cardiopulmonary resuscitation by bystanders with chest compression only (SOS-KANTO): an observational study. Lancet 2007;369:920-6.

6 Herlitz J, Bang A, Gunnarsson J, et al. Factors associated with survival to hospital discharge among patients hospitalised alive after out of hospital cardiac arrest: change in outcome over 20 years in the community of Goteborg, Sweden. Heart 2003;89:25-30.

7 The Public Access Defibrillation Trial Investigators. Public-access defibrillation and survival after out-of-hospital cardiac arrest. N Engl J Med 2004;351:637-46.

8 Kitamura T, Iwami T, Kawamura T, et al. Nationwide public-access defibrillation in Japan. N Engl J Med 2010;362:994-1004.

9 Nielsen AM, Folke F, Lippert FK, et al. Use and benefits of public access defibrillation in a nation-wide network. Resuscitation 2013;84:430-4.

10 Winkle RA. The effectiveness and cost effectiveness of public-access defibrillation. Clin Cardiol 2010;33:396-9.

11 Weisfeldt ML, Sitlani CM, Ornato JP, et al. Survival after application of automatic external defibrillators before arrival of the emergency medical system: evaluation in the resuscitation outcomes consortium population of 21 million. J Am Coll Cardiol 2010;55:1713-20.

12 Mosesso VN Jr, Shapiro AH, Stein K, et al. Effects of AED device features on performance by untrained laypersons. Resuscitation 2009;80:1285-9.

13 Vinnie Jones Hands-Only CPR. BHF video http://www.youtube.com/watch? $\mathrm{V}=$ ILxjxfB4zNk (accessed 18 Oct 2013).

14 Saving lives — our healthier nation. HSC 1999/152. 6 July 1999. http://webarchive. nationalarchives.gov.uk/20130107105354/http://www.dh.gov.uk/prod_consum_dh/ groups/dh_digitalassets/@dh/@en/documents/digitalasset/dh_4012579.pdf (accessed 18 Oct 2013).

15 Whitfield R, Colquhoun M, Chamberlain DA, et al. The Department of Health National Defibrillator Programme: analysis of downloads from 250 deployments of public access defibrillators. Resuscitation 2005;64:269-77. 
16 http://www.bhf.org.uk/heart-health/life-saving-skills/defibrillators.aspx (accessed 4 May 2013).

17 Moore MJ, Hamilton AJ, Cairns KJ, et al. The Northern Ireland Public Access Defibrillation (NIPAD) study: effectiveness in urban and rural populations. Heart 2008:94:1614-19.

18 Rea TD, Olsufka M, Bemis B, et al. A population-based investigation of public access defibrillation: role of emergency medical services care. Resuscitation 2010;81:163-7.

19 Colquhoun MC, Chamberlain DA, Newcombe RG, et al. A national scheme for public access defibrillation in England and Wales: early results. Resuscitation 2008;78:275-80.

20 Becker L, Eisenberg M, Fahrenbruch C, et al. Public locations of cardiac arrest. Implications for public access defibrillation. Circulation 1998;97:2106-9.

21 Frank RL, Rausch MA, Menegazzi JJ, et al. The locations of non-residential out-of-hospital cardiac arrests in the City of Pittsburgh over a three-year period: implications for automated external defibrillator placement. Prehosp Emerg Care 2001;5:247-51.

22 Koster RW, Baubin MA, Bossaert LL, et al. European Resuscitation Council Guidelines for Resuscitation 2010 Section 2. Adult basic life support and use of automated external defibrillators. Resuscitation 2010;81:1277-92.
23 Watson L, Gurkamal V, Fothergill R. Cardiac Arrest Annual Report: 2011/12 London Ambulance Service. http://www.londonambulance.nhs.uk/about_us/idoc.ashx? docid=445f8194-7174-4255-a37a-7f6c5bf2d75e\&version=-1 (accessed 4 May 2013).

24 Schober $\mathrm{P}$, van Dehn FB, Bierens JJ, et al. Public access defibrillation: time to access the public. Ann Emerg Med 2011;58:240-7.

25 Kozlowski D, Klosiewicz T, Kowalczyk A, et al. The knowledge of public access to defibrillation in selected cities in Poland. Arch Med Sci 2013;9:27-33.

$26 \mathrm{http}: / /$ www.carehome.co.uk/care_search_results.cfm/searchcounty/Hampshire (accessed 4 May 2013).

27 Sasaki M, Iwami T, Kitamura T, et al. Incidence and outcome of out-of-hospital cardiac arrest with public-access defibrillation. Circ J 2011;75:2821-6.

28 http://www.guardian.co.uk/news/datablog/2011/may/19/train-stations-listed-rail (accessed 4 May 2013).

$29 \mathrm{http}: / / w w w 3$.hants.gov.uk/factsandfigures/keyfactsandfigures/key-facts/fk-hepa.htm (accessed 4 May 2013).

30 Hazinski MF, Markenson D, Neish S, et al. Response to cardiac arrest and selected life-threatening medical emergencies: the medical emergency response plan for schools: a statement for healthcare providers, policymakers, school administrators, and community leaders. Circulation 2004;109:278-91. 